\title{
Study of the Frequency of Cardiovascular Diseases and Their Risk Factors in the Emergency Units of Two Hospitals in Dakar (Senegal)
}

\section{Pêngd-Wendé Habib Boussé Traore ${ }^{1,2 *}{ }^{\circledR}$, Jean Augustin Diegane Tine1, Oumar Bassoum1, Cheikh Tidiane Mbow ${ }^{3}$, Ababacar Diop${ }^{4}$, Abdoul Kane ${ }^{2}$, Adama Faye ${ }^{1}$}

${ }^{1}$ Institute of Health and Development, Public Health Service, Faculty of Medicine, Pharmacy and Odontology, Cheikh Anta Diop University, Dakar, Senegal

${ }^{2}$ Cardiology Department, Hôpital Dalal Jamm, Faculty of Medicine, Pharmacy and Odontology, Cheikh Anta Diop University, Dakar, Senegal

${ }^{3}$ Emergency Unit, Hôpital Principal de Dakar, Dakar, Senegal

${ }^{4}$ Emergency Unit, Hôpital de Pikine, Faculty of Medicine, Pharmacy and Odontology, Cheikh Anta Diop University,

Dakar, Senegal

Email: *traore.habib1990@gmail.com

How to cite this paper: Traore, P.-W.H.B., Tine, J.A.D., Bassoum, O., Mbow, C.T., Diop, A., Kane, A. and Faye, A. (2021) Study of the Frequency of Cardiovascular Diseases and Their Risk Factors in the Emergency Units of Two Hospitals in Dakar (Senegal). Open Journal of Internal Medicine, 11, 123139.

https://doi.org/10.4236/ojim.2021.113010

Received: July 4, 2021

Accepted: August 14, 2021

Published: August 17, 2021

Copyright $\odot 2021$ by author(s) and Scientific Research Publishing Inc. This work is licensed under the Creative Commons Attribution International License (CC BY 4.0).

http://creativecommons.org/licenses/by/4.0/ (c) (i) Open Access

\begin{abstract}
Introduction: Cardiovascular diseases constitute the deadliest pathology in the world with $31 \%$ of global mortality in 2018 . This is how we felt it necessary to conduct a study on cardiovascular diseases in emergency units of Senegal, more precisely in Dakar, in order to know epidemiological profile of these patients. Methods: The study setting was the reception and emergency units of the Hôpital de Pikine and Hôpital Principal de Dakar. This was an observational, descriptive cross-sectional study with an analytical aim to search for factors associated with the occurrence of cardiovascular disease. The study ran from January 25th to February 5th, 2018 at the Hôpital de Pikine and from February 25th to March 5th, 2018 at Hôpital Principal de Dakar. The source population consisted of patients over 18 years of age and not in a state of pregnancy, who were been received there and had given their free and informed consent to participate in the survey. A representative sample had drawn and a consecutive recruitment of eligible patients were been carried out. The data collection tools were been based on the WHO STEPwise survey questionnaire. Data collection was been carried out in accordance with ethical rules. Results: The study involved 615 patients. The proportions of sedentary lifestyle, low daily consumption of fruits/vegetables, overweight and obesity were $72.4 \%, 96.4 \%, 22.7 \%$ and $17.3 \%$ respectively. This was $55.5 \%$ of women who had a waist circumference that corresponded to a high risk of
\end{abstract}


a cardiovascular event and $10.2 \%$ for men. $38.9 \%$ of patients had blood pressure above $140 / 90 \mathrm{mmh}$ and $32.2 \%$ said they had never controlled their blood pressure in their life. The use of a consultation in a health structure to control his blood pressure was by far the most frequent modality with $61.4 \%$. The proportion of people with cardiovascular disease was $50.1 \%$. Hypertensive flare-ups/hypertensive emergencies were the leading complications diagnosed with $33.33 \%$. Factors associated with the occurrence of cardiovascular disease were sex, age, professional status and body mass index. Discussion \& Conclusion: The risk factors for cardiovascular disease are highly represented in our emergency units. In addition to the available care offer, the identification of factors associated with the occurrence of cardiovascular diseases in patients who are been seen there will allow targeted preventive actions within this fragile and vulnerable population. All this to help achieve target 3.4 of the Sustainable Development Goals (SDGs) by 2030. Furthermore, according to the associated factors identified, it appears that achieving SDG 8 will greatly contribute to the prevention of cardiovascular disease. This proves the urgency and interest of an integrated multi-ministerial vision in our strategic plans for the prevention against major non-communicable diseases and cardiovascular diseases in particular.

\section{Keywords}

Risk Factors, Cardiovascular Diseases, Emergency Units, Senegal

\section{Introduction}

The twenty-first century is the scene of a more marked epidemiological transition in Africa [1]. We are witnessing the galloping evolution of major noncommunicable diseases (NCDs) in general with cardiovascular diseases (CVD) such as Myocardial infarction (MI), heart failure (HF), cerebrovascular accidents (stroke) and high blood pressure (hypertension) [2].

CVD is the deadliest pathology in the world [3] with $31 \%$ of the global mortality in 2018 [1] [4] [5] [6], of which three quarters of deaths occurred in lowand middle-income countries [1]. It is predicted that by $2030,82 \%$ of the increase in coronary heart disease mortality will occur in these same countries [1] [7]. In Senegal, CVD mortality was 10\% in 2014 according to the World Health Organization (WHO) [8] [9].

While population-based CVD surveys have been carried out, the epidemiological profile of patients received in emergency units (EU) is not clearly established. This is probably related to the fact that in sub-Saharan Africa, emergency medicine is not yet a properly promoted specialty [10].

This is how it appeared necessary to us to conduct a study on the epidemiology of CVD in the EU of Senegal, more precisely in Dakar.

The objective of this study was to determine the proportion of CVD and the factors associated with them in the population of patients received in the EU of Dakar hospitals. 


\section{Methodology}

\subsection{Study Framework}

We selected the UAA of the Hôpital de Pikine (HP) and Hôpital Principal de Dakar (HPD) as our study framework for the following reasons:

The Dakar region is the most populous region of Senegal [11] with $23.13 \%$ of the total population in 2017 [12]. In the Dakar region, the departments of Pikine and Dakar together contain more than $60 \%$ of its population [12] and are home respectively to HP and HPD. They are both level 3 public health facilities, with an EU that receives both medical and surgical emergencies.

In addition, HP, which is located in the Dakar suburbs, mainly hosts a population with a low socio-economic level and, in contrast, HPD, located in the most developed urban center of Dakar, mainly hosts a population with a high socio-economic level.

\subsection{Type and Period of Study}

It was a cross-sectional, descriptive, analytical study. We collected data from January 25th to February 5th, 2018 at HP and from February 25th to March 05th, 2018 at HPD.

\subsection{Study Population}

The target population consisted of patients seen in consultation in the two EU.

The source population was defined with the inclusion criterion which was to be at least 18 years old and the exclusion criteria which were the refusal to participate in the survey, the fact of arriving dead in the EU or being pregnant.

\subsection{Sampling}

The sample size was calculated according to the following formula [13]

$$
n_{0}=\varepsilon^{2} \cdot \frac{P(1-P)}{i^{2}}
$$

$\mathcal{E}=1.96$ for a risk of error of the first kind $\alpha=5 \%$

$P=$ expected proportion of patients with cardiovascular diseases among those admitted to EU (50\%)

$i=$ precision $(5 \%)$

$$
n_{0}=1.96^{2} \cdot \frac{0.5(1-0.5)}{0.05^{2}}=384
$$

A review of the consultation registers of the two EU revealed that the average number of patients that admitted to each EU was 25 per day. Thus, the expected size $(N)$ of the target population was 750 patients per month. Since this number was less than 10,000, the sample size was adjusted $(n)$ according to the following formula:

$$
n=\frac{n_{0}}{1+\frac{n_{0}}{N}}=\frac{284}{1+\frac{384}{750}}=254
$$


In anticipation of non-respondents (10\%), the minimum sample size retained was 280 patients in each EU.

The sampling procedure. This was a consecutive recruitment of eligible patients during the study period until the required sample size was reached for each study site.

\subsection{Data Collection Tool}

The data collection tools were based on the WHO STEPwise survey questionnaire [14]. It included:

On the one hand, a questionnaire composed of four sections with sociodemographic characteristics (age, sex, marital status, level of education, professional status), the behavioural characteristics of the patient (consumption of fruits/vegetables and physical activity), the profile of patients with CVD, the length of time and treatment of hypertension, methods of controlling blood pressure

On the other hand, a form had two sections. The first allowed collecting anthropometric parameters with weight, height, waist circumference, body mass index and blood pressure. The second was to collect the type of CVD complication diagnosed with the EU.

Note that these collection tools have been test at the EU at Hôpital de FANN.

\subsection{Collection Method}

Data collection was done in the sorting room of each EU. The questionnaire was administered during a face-to-face interview with each patient. The form was completed using standardized and approved materials.

The weight was measured in all subjects wearing a minimum of clothing and standing upright on a SECA brand mechanical scale deposited on a horizontal plane, calibrated with a unit graduation in $\mathrm{Kg}$, ranging from 0 to $150 \mathrm{Kg}$.

The height was measured in all subjects in an upright position, back against the wall, heels together, without shoes and looking straight ahead with a SECA 206 brand wall measuring board with metal tape ranging from 0 to $220 \mathrm{~cm}$, with a unit graduation of $1 \mathrm{~mm}$.

Waist circumference was measured in all subjects in a standing position with their legs apart approximately $25 \mathrm{~cm}$ to $30 \mathrm{~cm}$. The measurement was made halfway between the lower limit of the thoracic cage and the iliac crest with a flexible, non-stretchy tape measure graduated in $\mathrm{mm}$.

The blood pressure (BP) was measured with an OMRON model M6 Comfort brand electronic blood pressure monitor expressing systolic blood pressure (SBP) and diastolic blood pressure (DBP) in mmHg. The measurement was made in the subject in a supine position, after resting at least 10 minutes in the right arm and then in the left arm. This was repeated 3 times, with an interval of three minutes between measurements. Only the measurement with the largest values of SBP and DBP was retained. 
The form was also completed using medical records. These were used to collect data relating to the type of CVD complication diagnosed.

\subsection{Operational Definitions of Variables}

\section{Fruit and vegetable consumption}

From the participant's statements, the quantity of consumption was evaluated with three items: 1 to 2 fruits and vegetables, 3 to 4 fruits and vegetables, 5 fruits and vegetables or more. The frequency of use was assessed using the five-point Likert scale [15]. Insufficient fruit and vegetable consumption was retained for any consumption of less than 5 fruits and/or vegetables per day [2] [16].

\section{Physical activity}

Sufficient physical activity is defined as moderate-intensity endurance physical activity with a threshold duration of 150 minutes per week or 75 minutes of sustained-intensity endurance activity per week [16] [17]. Insufficient physical activity is defined for any duration below the threshold recommended [2] [17].

\section{Body mass index}

The body mass index (BMI) was calculated by the weight $(\mathrm{Kg}) / \mathrm{height}^{2}\left(\mathrm{~m}^{2}\right)$ ratio. The BMI was classified into the following categories: thinness if BMI < $18.5 \mathrm{Kg} / \mathrm{m}^{2}$, normal if BMI between 18.5 and $24.9 \mathrm{Kg} / \mathrm{m}^{2}$, overweight if BMI between 25 and $29.9 \mathrm{Kg} / \mathrm{m}^{2}$ and obesity if $\mathrm{BMI} \geq 30 \mathrm{Kg} / \mathrm{m}^{2}$ [14] [16] [18].

\section{Abdominal obesity}

A waist circumference threshold greater than $102 \mathrm{~cm}$ for men and $88 \mathrm{~cm}$ for women has been used according to WHO criteria to define abdominal obesity [14] [16] [18].

\section{Classification of blood pressure values}

According to the 1999 WHO classification of hypertension in adults [19] [20] [21] [22] as:

We considered as having optimal blood pressure any subject with SBP $<120$ $\mathrm{mmHg}$ and $\mathrm{DBP}<80 \mathrm{mmHg}$ [9] [23].

We considered as having normal blood pressure, any subject with $120 \mathrm{mmHg}$ $\leq$ PAS $<130 \mathrm{mmHg}$ and $80 \mathrm{mmHg} \leq \mathrm{DBP}<85 \mathrm{mmHg}$ [9] [23].

We considered as having normal high blood pressure, any subject with 130 $\mathrm{mmHg} \leq \mathrm{PAS}<140 \mathrm{mmHg}$ and/or $85 \mathrm{mmHg} \leq \mathrm{DBP}<90 \mathrm{mmHg}$ [9] [23].

We considered hypertensive any subject with $\mathrm{SBP} \geq 140 \mathrm{mmHg}$ and/or DBP $\geq$ $90 \mathrm{mmHg}$ [9] [23] or under antihypertensive treatment [18].

We considered as grade I hypertension, any subject with $140 \mathrm{mmHg} \leq \mathrm{PAS}<$ $160 \mathrm{mmHg}$ and/or $90 \mathrm{mmHg} \leq \mathrm{DBP}<100 \mathrm{mmHg}$ [9] [23].

We considered as grade II hypertension any subject with $160 \mathrm{mmHg} \leq \mathrm{PAS}<$ $180 \mathrm{mmHg}$ and/or $100 \mathrm{mmHg} \leq \mathrm{DBP}<110 \mathrm{mmHg}$ [9] [23].

We considered as grade III hypertension, any subject with SBP $\geq 180 \mathrm{mmHg}$ and/or DBP $\geq 110 \mathrm{mmHg}$ [9] [23].

The state of shock is defined for any PAS $<70 \mathrm{mmHg}$ with signs of organic hypo perfusion (cyanosis, polypnea, small pulsating pulse, coldness of the extremities, broken diuresis). 


\section{Cardiovascular diseases}

For patients with hypertension, IDM and heart failure, data were obtained from participant reports or specific treatment for the heart disease.

With regard to cerebrovascular accidents (strokes): these are ischemic and haemorrhagic strokes. The data were obtained from the participant's statements, from the specific treatment, or from the presence of a neurological deficit associated with CT images of stroke [24].

\section{Proportions}

The proportion of CVD was calculated by adding the known cases and the newly diagnosed cases.

\subsection{Statistical Analyses}

The analysis was carried out with the Statistical Package for Social Sciences version 18 (SPSS 18) software and included a descriptive and analytical part.

The descriptive part consisted in expressing the quantitative variables in the form of the mean with its standard deviation and the framed median of the extreme values and the mode. Qualitative variables were expressed with their absolute and relative frequencies.

The analytical part included bivariate analysis and multivariate analysis. The bivariate analysis consisted only of the comparison of unpaired proportions. The objective was to find the existence of a statistically significant association between the independent (explanatory) variables with the binary dependent variable, which is occurrence of cardiovascular diseases (yes/no). The presence of a statistically significant link was retained for a $\mathrm{p}$-Value $\leq 0.05$. This link was sought with the appropriate statistical test (parametric test or nonparametric test) according to its conditions of applicability.

Multivariate analysis was performed with independent variables whose $\mathrm{p}$-values were $<0.25$ in the bivariate analysis. Using logistic regression, it identified the factors associated with the occurrence of cardiovascular disease. A given independent variable was retained as a factor associated with the occurrence of cardiovascular disease when it had a $\mathrm{p}$-Value $\leq 0.05$. When this was true, we continued the interpretation with the value of the Odds Ratio (OR) surrounded by its $95 \%$ confidence interval ( $95 \% \mathrm{CI})$. The associated factor was considered a risk factor when the $\mathrm{OR}>1$. Otherwise, the factor was said to be protective against the onset of cardiovascular disease.

\subsection{Ethical Considerations}

The study had received clearance from the heads of the SAU department. Compliance with the ethical framework was also achieved through a clear, complete and precise information text that presented the context and the aim of the study for the free and informed consent of the participants. The consent was signed. In addition, data collection was carried out with confidentiality and strict respect for the privacy of the participant. Subsequently, access to the data collected was limited exclusively to the analyst, which ensured the confidentiality of the data. 


\section{Results}

In total, those are 615 patients who were included: $53.7 \%$ with HPD and $46.3 \%$ with HP (Table 1).

Table 1. Sociodemographic, behavioural and anthropometric characteristics of patients in the study of the frequency of cardiovascular diseases and their risk factors in the emergency units of two hospitals in Dakar (Senegal) in 2018.

\begin{tabular}{|c|c|c|}
\hline Variables and modalities & Absolute frequencies (n) & Relative frequencies (\%) \\
\hline \multicolumn{3}{|l|}{ Hospital } \\
\hline Hôpital Principal de Dakar & 330 & 53.7 \\
\hline Hôpital de Pikine & 285 & 46.3 \\
\hline \multicolumn{3}{|l|}{ Sex } \\
\hline Man & 322 & 52.4 \\
\hline Women & 293 & 47.6 \\
\hline \multicolumn{3}{|l|}{ Age class in years } \\
\hline$<40$ & 272 & 44.4 \\
\hline$[40-69]$ & 235 & 38.3 \\
\hline$\geq 70$ & 106 & 17.3 \\
\hline \multicolumn{3}{|l|}{ Marital status } \\
\hline Married & 397 & 64.5 \\
\hline Not married & 218 & 35.4 \\
\hline \multicolumn{3}{|l|}{ Level of study } \\
\hline No & 153 & 25.5 \\
\hline Primary & 155 & 25.8 \\
\hline Secondary & 192 & 32.0 \\
\hline Superior & 100 & 16.7 \\
\hline \multicolumn{3}{|l|}{ Professional status } \\
\hline Employment & 285 & 46.7 \\
\hline Without employment & 325 & 53.3 \\
\hline \multicolumn{3}{|l|}{ Physical activity } \\
\hline Sufficient & 170 & 27.6 \\
\hline Insufficient & 445 & 72.4 \\
\hline \multicolumn{3}{|l|}{ Fruit and vegetable consumption } \\
\hline Sufficient & 22 & 3.6 \\
\hline Insufficient & 593 & 96.4 \\
\hline \multicolumn{3}{|l|}{ Body mass index class } \\
\hline Thinness & 84 & 14.9 \\
\hline Normal & 255 & 45.1 \\
\hline Overweight & 128 & 22.7 \\
\hline Obesity & 98 & 17.3 \\
\hline
\end{tabular}




\subsection{Sociodemographic Characteristics (Table 1)}

Men were in the majority with $52.4 \%$. Patients under 40 years of age accounted for $44.4 \%$ in our study. According to marital status, married people were in the majority with $64.5 \%$ and $32.0 \%$ of our patients were at the secondary school level. The proportion of employed patients was $46.7 \%$.

\subsection{Behavioural Characteristics (Table 1)}

In our study, $72.4 \%$ of respondents did not engage in sufficient physical activity. In addition, only $3.6 \%$ of patients reported consuming at least 5 fruits/vegetables per day.

\subsection{Anthropometric Characteristics (Table 1)}

Our study revealed $22.7 \%$ of overweight and $17.3 \%$ obese patients. The mean waist circumference was $87.8 \pm 14.3 \mathrm{~cm}$ and a median of $87 \mathrm{~cm}$ with extremes of 40 to $155 \mathrm{~cm}$. The mode was $90 \mathrm{~cm}$. According to sex, the average waist circumference was $89.85 \mathrm{~cm}$ for women against $85.10 \mathrm{~cm}$ for men.

\subsection{Blood Pressure Values (Table 2)}

The mean SBP was $130 \mathrm{mmHg} \pm 2.6 \mathrm{mmHg}$ and the median $130 \mathrm{mmHg}$ with values oscillating between 60 and $250 \mathrm{mmHg}$. The mode was $120 \mathrm{mmHg}$.

The mean DBP was $80 \mathrm{mmHg} \pm 1.6 \mathrm{mmHg}$ and the median was $80 \mathrm{mmHg}$ with extreme values of 40 to $180 \mathrm{mmHg}$. The mode had the same value as the median is $80 \mathrm{mmHg}$.

The proportion of patients whose blood pressure classified them in the hypertension category ( $\mathrm{SBP}>140 \mathrm{mmHg}$ and/or $\mathrm{DBP}>90 \mathrm{mmHg}$ ) was $38.9 \%$.

With respectively $18.20 \%$ for HTA grade I; $12 \%$ for grade II hypertension and $8.70 \%$ for grade III hypertension.

\subsection{History of High Blood Pressure (Table 2)}

Of the 615 patients in the study, $23.9 \%$ had known hypertension; $10.6 \%$ of patients said they did not know whether they had hypertension or not and $65.5 \%$ said they were sure they did not.

\subsection{Duration of Arterial Hypertension (Table 2)}

The duration of hypertension was been documented in 136 of the 147 patients who were known to be hypertensive. The mean was 109.6 months (9.13 years). The median was 84 months with extremes of $1 / 2$ month to 480 months. The mode was 120 months.

\subsection{Ongoing Treatment for High Blood Pressure (Table 2)}

Of the 147 known hypertensive patients, 120 were on treatment (81.6\%). Among them, the most common therapeutic modality was taking oral antihypertensive drugs with $97.5 \%$. 
Table 2. Clinical and therapeutic characteristics of patients in the study of the frequency of cardiovascular diseases and their risk factors in the emergency units of two hospitals in Dakar (Senegal) in 2018.

\begin{tabular}{|c|c|c|}
\hline Variables and modalities & Absolute frequencies (n) & Relative frequencies (\%) \\
\hline \multicolumn{3}{|l|}{ Classification according to SBP and DBP } \\
\hline State of shock & 11 & 1.8 \\
\hline Optimal BP & 136 & 22.3 \\
\hline Normal BP & 115 & 18.9 \\
\hline BP normal high & 110 & 18.1 \\
\hline HBP grade I & 111 & 18.2 \\
\hline HBP grade II & 73 & 12.0 \\
\hline HBP grade III & 53 & 8.7 \\
\hline \multicolumn{3}{|l|}{ Known history of high blood pressure } \\
\hline Yes & 147 & 23.9 \\
\hline No & 403 & 65.5 \\
\hline Do not know & 65 & 10.6 \\
\hline \multicolumn{3}{|c|}{ Treatment of high blood pressure in patients with known hypertension ${ }^{*}$} \\
\hline Anti-hypertensive & 117 & 97.5 \\
\hline Diet & 21 & 17.5 \\
\hline Herbal medicine & 4 & 3.3 \\
\hline \multicolumn{3}{|l|}{ Frequency of blood pressure monitoring } \\
\hline Never & 198 & 32.2 \\
\hline Rarely & 102 & 16.6 \\
\hline Occasionally & 220 & 35.8 \\
\hline Often & 83 & 13.5 \\
\hline Always & 12 & 2.0 \\
\hline \multicolumn{3}{|l|}{ Blood pressure monitoring mode } \\
\hline In a health facility & 252 & 61.3 \\
\hline In a drug store & 121 & 29.4 \\
\hline By Auto measure & 44 & 10.7 \\
\hline \multicolumn{3}{|l|}{ History of stroke } \\
\hline Yes & 16 & 2.6 \\
\hline No & 599 & 97.4 \\
\hline \multicolumn{3}{|l|}{ History of heart failure } \\
\hline Yes & 28 & 4.6 \\
\hline No & 587 & 95.4 \\
\hline \multicolumn{3}{|l|}{ History of myocardial infarction } \\
\hline Yes & 1 & 0.1 \\
\hline No & 614 & 99.9 \\
\hline \multicolumn{3}{|l|}{ Diagnosed complications of cardiovascular disease } \\
\hline Myocardial infarction & 03 & 4.4 \\
\hline Hypertensive Flare/Hypertensive Emergency & 23 & 33.3 \\
\hline Decompensated heart failure & 22 & 31.9 \\
\hline Stroke & 21 & 30.4 \\
\hline
\end{tabular}

${ }^{\star} \mathrm{NB}$ : a patient can be counted several times. 


\subsection{Blood Pressure Monitoring (Table 2)}

Out of all 615 patients in the study, more than a third of patients $(32.2 \%)$ said they had never had their blood pressure checked in their entire life (198 patients).

\subsection{Blood Pressure Monitoring Mode (Table 2)}

Of the remaining 417 patients (those who have already checked their BP at least once in their life), the use of a consultation in a health facility to control BP was by far the most frequent modality with $61.4 \%$, then came the use of pharmacy with $29.4 \%$ and finally self-measurement with $10.7 \%$.

\subsection{Known History of Stroke (Table 2)}

Out of all 615 patients in the study, $2.6 \%$ had a history of stroke.

\subsection{Known History of Myocardial Infarction (Table 2)}

Only one patient out of 615 had a history of heart attack.

\subsection{Known History of Heart Failure (Table 2)}

Out of all 615 patients in the study, heart failure was been noted in 28 patients, or $4.6 \%$.

\subsection{Proportion of Cardiovascular Disease}

In our study, the proportion of people with cardiovascular disease was $50.1 \%$ (old + new).

\subsection{Complications of Diagnosed Cardiovascular Disease (Table 2)}

These 69 patients presented with CVD complications. These complications were in decreasing order of frequency: hypertensive outbreaks/hypertensive emergencies with $33.33 \%$, IC decompensations with $31.88 \%$ then strokes with $30.43 \%$ and finally IDM with $4.35 \%$.

\subsection{Bivariate Analyses (Table 3)}

There were statistically significant associations between the occurrence of cardiovascular diseases with respectively: age ( $\mathrm{p}$-Value $<0.0001)$; marital status $(\mathrm{p}$-Value $=0.0015)$; level of study $(\mathrm{p}$-Value $=0.00025) ;$ professional status $(\mathrm{p}$-Value $=0.00066) ;$ physical activity $(\mathrm{p}$-Value $=0.0036)$ and BMI $(\mathrm{p}$-Value $<$ 0.0001).

\subsection{Multivariate Analyses (Table 4)}

Factors associated with the occurrence of CVD in our study were: Gender, age, existence of a job and BMI.

Being female was protective. Women were 2.24 times less likely to have car- 
diovascular disease compared to men ( $\mathrm{p}-$ Value $=0.0015 ; 95 \% \mathrm{CI}=[0.27-0.73])$.

Being between 40 and 69 years old increased the risk of having cardiovascular disease by 2.83 times compared to those under 40 (p-Value $<0.0001 ; 95 \% \mathrm{CI}=$ [1.75 - 4.58]).

Table 3. Bivariate analysis of the occurrence of cardiovascular diseases in the study of the frequency of cardiovascular diseases and their risk factors in the emergency units of two hospitals in Dakar (Senegal) in 2018.

\begin{tabular}{|c|c|c|c|c|c|}
\hline \multirow[t]{3}{*}{ Variables and modalities } & \multicolumn{4}{|c|}{ Cardiovascular disease } & \multirow[t]{3}{*}{ p-Value } \\
\hline & \multicolumn{2}{|c|}{ YES } & \multicolumn{2}{|c|}{ NO } & \\
\hline & Effective & $\%$ & Effective & $\%$ & \\
\hline Sex & & & & & 0.1262 \\
\hline Man & 137 & 55.2 & 127 & 48.5 & \\
\hline Women & 111 & 44.8 & 135 & 51.5 & \\
\hline Age class in years & & & & & $<0.0001$ \\
\hline$<40$ & 66 & 26.6 & 163 & 62.2 & \\
\hline$[40-69]$ & 112 & 45.2 & 79 & 30.2 & \\
\hline$\geq 70$ & 70 & 28.2 & 20 & 7.6 & \\
\hline Marital status & & & & & 0.0015 \\
\hline Married & 178 & 71.8 & 153 & 58.4 & \\
\hline Not married & 70 & 28.2 & 109 & 41.6 & \\
\hline Level of study & & & & & 0.00025 \\
\hline No & 96 & 32.1 & 57 & 18.9 & \\
\hline Primary & 79 & 26.4 & 76 & 25.2 & \\
\hline Secondary & 88 & 29.4 & 104 & 34.6 & \\
\hline Superior & 36 & 12.0 & 64 & 21.3 & \\
\hline Professional status & & & & & 0.00066 \\
\hline Employment & 98 & 39.5 & 143 & 54.6 & \\
\hline Without employment & 150 & 60.5 & 119 & 45.4 & \\
\hline Fruit and vegetable consumption & & & & & 0.165 \\
\hline Sufficient & 21 & 8.5 & 32 & 12.2 & \\
\hline Insufficient & 227 & 91.5 & 230 & 87.8 & \\
\hline Physical activity & & & & & 0.0036 \\
\hline Sufficient & 48 & 19.4 & 80 & 30.5 & \\
\hline Insufficient & 200 & 80.6 & 182 & 69.5 & \\
\hline Body mass index & & & & & $<0.0001$ \\
\hline Thinness & 35 & 15.4 & 39 & 15.7 & \\
\hline Normal & 83 & 36.6 & 137 & 55.2 & \\
\hline Overweight & 57 & 25.1 & 54 & 21.8 & \\
\hline Obesity & 52 & 22.9 & 18 & 7.3 & \\
\hline
\end{tabular}


Table 4. Multivariate analysis of the occurrence of cardiovascular diseases in the study of the frequency of cardiovascular diseases and their risk factors in the emergency units of two hospitals in Dakar (Senegal) in 2018.

\begin{tabular}{|c|c|c|c|}
\hline Variables and modalities & $\mathrm{OR}_{\mathrm{a}}$ & $\mathrm{CI}^{95 \%}$ & p-Value \\
\hline Sex & & & 0.0015 \\
\hline Man & 1 & & Reference \\
\hline Women & 0.44 & {$[0.27-0.73]$} & 0.0015 \\
\hline Age class in years & & & $<0.0001$ \\
\hline$<40$ & 1 & & Reference \\
\hline$[40-69]$ & 2.83 & {$[1.75-4.58]$} & $<0.0001$ \\
\hline$\geq 70$ & 6.16 & {$[3.00-12.66]$} & $<0.0001$ \\
\hline Level of study & & & 0.44 \\
\hline No & 1 & & Reference \\
\hline Primary & 0.72 & {$[0.38-1.36]$} & 0.31 \\
\hline Secondary & 0.87 & {$[0.47-1.62]$} & 0.66 \\
\hline Superior & 0.59 & {$[0.29-1.19]$} & 0.14 \\
\hline Professional status & & & 0.03 \\
\hline Employment & 1 & & Reference \\
\hline Unemployed & 1.68 & {$[1.05-2.67]$} & 0.03 \\
\hline Marital status & & & 0.46 \\
\hline Married & 1 & & Reference \\
\hline Not married & 0.84 & {$[0.52-1.34]$} & 0.46 \\
\hline Physical activity & & & 0.97 \\
\hline Sufficient & 1 & & Reference \\
\hline Insufficient & 1.01 & {$[0.59-1.73]$} & 0.97 \\
\hline Fruit and vegetable consumption & & & 0.12 \\
\hline Sufficient & 1 & & Reference \\
\hline Insufficient & 1.73 & {$[0.86-3.48]$} & 0.12 \\
\hline Body mass index & & & $<0.0001$ \\
\hline Normal & 1 & & Reference \\
\hline Thinness & 1.38 & {$[0.76-2.50]$} & 0.29 \\
\hline Overweight & 1.89 & {$[1.13-3.17]$} & 0.015 \\
\hline Obesity & 7.25 & {$[3.59-14.65]$} & $<0.0001$ \\
\hline
\end{tabular}

Being over 70 years of age increased the risk of developing cardiovascular disease by 6.165 times compared to those under 40 (p-Value $<0.0001 ; 95 \% \mathrm{CI}=$ [3.00 - 12.66]).

Being overweight increased the risk of developing cardiovascular disease by 1.9 times compared to those with a normal BMI $(\mathrm{p}$-Value $=0.015 ; 95 \% \mathrm{CI}=$ [1.13 - 3.17]). 
Being obese increased the risk of having cardiovascular disease by 7.25 times compared to those with a normal BMI (p-Value $<0.0001 ; 95 \% \mathrm{CI}=[3.59-$ 14.65]).

Being unemployed was a risk factor compared to those who were been employed. It increased the risk of developing cardiovascular disease by 1.68 times $(\mathrm{p}-$ Value $=0.03 ; 95 \% \mathrm{CI}=[1.05-2.67])$.

\section{Discussion}

The proportions of patients with insufficient physical activity (72.4\%), with a low consumption of fruits and vegetables (96.5\%) were higher than the prevalence encountered in the general Senegalese [23], Burkinabè [25], Ivorian [26], Togolese [27], Malian [28], Mauritanian [29] and Beninese population [30].

Proportions of patients with overweight $(22.7 \%)$ and obesity (17\%) were also higher than the prevalence in general population of these countries with the exception of Malian population [28], Mauritanian [29] and Beninese [30].

The proportion of patients with BP with SBP $\geq 140$ and/or DBP $\geq 90 \mathrm{mmHg}$ was $38.90 \%$ in our EU population. This proportion was much higher than the prevalence obtained in the general population of Senegal (24\%) [23], Burkina (17.6\%) [25], Ivory Coast (25.9\%) [26], Mali (22.1\%) [28], Mauritania (22.4\%) [29], Benin (27.3\%) [30] [31], Togo (19\%) [27], and even of Tunis [32].

More frightening was the fact that in the 21st century, in the boom of NCDs, in 615 patients seen at the emergency units; more than a third (32.2\%) said they had never controlled their BP in their life. Indeed, rare are the consultations where all the information is been cheeked rigorously. Much can be done to raise awareness of the value of monitoring blood pressure levels for the prevention and management of hypertension and its complications.

To support the urgency of the need to monitor blood pressure figures, our study tells us that hypertensive flare-ups/hypertensive emergencies were the leading cardiovascular disease complications diagnosed in EU with 33.33\%. The study carried out in Kinshasa's medical emergencies in 2014 already showed us that cardiovascular diseases were a predictor of mortality in emergency units [33].

Moreover, this study shows that among the patients who had already control their BP at least once in their life, the use of a consultation in a health structure was by far the most frequent modality to control their BP with $61,3 \%$ then the measurement in pharmacies (29.4\%) and finally the self-measurement $(10.7 \%)$. This distribution, to the detriment of the methods of measurement in pharmacy and self-measurement, shows us an interest in understanding the mentality of our populations on these methods of controlling BP.

Is it a knowledge problem about being able to control your BP in the pharmacy or by yourself or is it more a matter of trust?

Is this a problem of economic power because the cost of measuring $\mathrm{BP}$ in pharmacies is higher than that in a health structure and the price for the acquisi- 
tion of self-measuring BP equipment remains out of scope for certain purses. Finally, in the specific case of self-measurement, is it a problem of knowledge about the measurement technique and/or the interpretation of the results?

It is more than important to understand the reasons for this reality because the prevalence of arterial hypertension is growing in our countries as already shown by the study carried out in a cardiology unit in Lomé, which attested that arterial hypertension was the most frequent affection among admissions from 2004 to 2009 [34].

The factors associated with the occurrence of CVD in our study were, on the one hand, non-modifiable factors (gender and age) and on the other hand, modifiable factors (existence of a job and BMI).

Being female was protective; women for physiological (female hormones) and social (less stress due to lower level of social responsibilities) reasons are found to be less at risk for cardiovascular conditions than men. This is why being male is considered a risk factor in cardiology.

Being between 40 and 69 years of age increased the risk by 2.83 times and being over 70 increased the risk of developing cardiovascular disease by 6.165 times compared to those under 40 years of age. The older we get, the more chances we have of developing cardiovascular disease, indeed several phenomena make this true, in particular with atherosclerosis, which evolves with age and thus weakens the vessels and the heart. In our study, being overweight increased the risk by 1.9 times and being obese increased the risk of developing cardiovascular disease by 7.25 times compared to those with a normal BMI. Being overweight is the bed by predilection for metabolic syndrome, which leads to cardiovascular disease.

Being unemployed was a risk factor compared to those who were employed. It increased the risk of developing cardiovascular disease by 1.68 times. We explain this by the fact that being unemployed causes stress and inactivity, which is highly prone to cardiovascular disease.

\section{Conclusions}

Cardiovascular disease is the leading cause of death in the world and is a frequent cause of consultation in emergency units. This study provides data on the factors associated with cardiovascular diseases in patients received in these emergency units in Senegal in order to improve the primary prevention of these diseases and their complications in this particular population.

It is more than urgent that the populations adopt a healthy lifestyle in order to effectively prevent cardiovascular diseases, to regularly monitor their blood pressure and their anthropometric parameters. Practitioners would benefit from making the measurement of blood pressure and body mass index systematic in all patients, regardless of their reasons for consultation, and each time seizing the opportunity to educate each patient who arrives in the emergency unit on the issues of cardiovascular diseases and their risk factors. The fight for the pri- 
mary prevention of cardiovascular diseases and non-communicable diseases in general remains a multi-ministerial challenge.

\section{Limitations of the Study}

Our study has a limitation that should be noted: The religious, social and hospital context exposed strongly to prevarication and social desirability biases with regard to alcohol consumption and smoked tobacco. This explains why these two aspects were not taken into account in analyzes.

\section{Authors' Contribution}

The study protocol was written by Pêngd-Wendé Habib Boussé TRAORE and Oumar BASSOUM. The field survey, data entry and analysis were carried out by Pêngd-Wendé Habib Boussé TRAORE. The manuscript was written by PêngdWendé Habib Boussé TRAORE, Oumar BASSOUM and Jean Augustin Diegane TINE. The validation of the protocol, the supervision of the field survey and the correction of the manuscript were carried out by Jean Augustin Diegane TINE, Abdoul KANE and Adama FAYE. Cheikh Tidiane MBOW, Ababacar DIOP had granted authorization to investigate in their respective emergency units.

\section{Acknowledgements}

Institute of Health and Development; Emergency unit of Hôpital de Pikine; Emergency unit of Hôpital Principal de Dakar.

\section{Conflicts of Interest}

The authors declare no conflicts of interest regarding the publication of this paper.

\section{References}

[1] Fourcade, L. (2007) Epidemiological Transition and Development: Is the Rise of Non-Communicable Diseases Inevitable? Medecine Tropicale, 67, 543-544.

[2] Houehanou, Y.C.N. (2015) Epidemiology of Cardiovascular Risk Factors in Tropical Populations-Case of Benin. PhD Thesis, Universities of Limoges Cotutelle AbomeyCalavi, Benin.

[3] PiLeJe Micronutrition. Cardiovascular Diseases: Definition and Examples. http://www.pileje-micronutrition.fr/Maladies-cardiovasulaires

[4] Markbreiter, J. and Buckley, P. (2016) CVD Advocacy Toolkit the Road to 2018. World Heart Federation, Geneva, 32 p. http://www.worldheart.org

[5] AFCAO. AFCAO-WHO Survey. http://www.afcao.org/who.htm

[6] World Heart Federation. https://www.world-heart-federation.org/

[7] World Health Organization, World Heart Federation and World Stroke Organization (2011) Global Atlas on Cardiovascular Disease Prevention and Control Policies, Strategies and Interventions. World Health Organization, Geneva, 164 p.

[8] World Health Organization (2014) Global Status Report on Noncommunicable Diseases 2014. World Health Organization, Geneva. 
[9] Aubry, P. and Gaüzère, B.-A. (2016) Heart Disease in the Tropics: News 2015. Médecine Tropicale.

[10] Myers, J.G., Hunold, K.M., Ekernas, K., Wangara, A., Maingi, A., Mutiso, V., et al. (2017) Patient Characteristics of the Accident and Emergency Department of Kenyatta National Hospital, Nairobi, Kenya: A Cross-Sectional, Prospective Analysis. BMJ Open, 7, e014974. https://doi.org/10.1136/bmjopen-2016-014974

[11] Volontaire France (2008) Exchanges and International Solidarity. Presentation of Senegal Region by Region.

[12] National Agency for Statistics and Demography (n.d.). http://www.ansd.sn/

[13] Charan, J. and Biswas, T. (2013) How to Calculate Sample Size for Different Study Designs in Medical Research? Indian Journal of Psychological Medicine, 35, 121-126. https://www.ncbi.nlm.nih.gov/pmc/articles/PMC3775042/

[14] World Health Organization, Department of Chronic Diseases and Health Promotion. WHO STEPS Questionnaire (Core and Extended Modules). https://www.who.int/ncds/surveillance/steps/Questionnaire.pdf

[15] Quint-Essenz (n.d.) Entry Page. https://www.quint-essenz.ch/fr

[16] World Health Organization, Regional Office for Africa (2016) Report on the Status of Major Health Risk Factors for Noncommunicable Diseases: WHO African Region, 2015. World Health Organization, Regional Office for Africa, Brazzaville, 88 p. http://www.afro.who.int/en/clusters-a-programmes/hpr/health-risk-factors.html

[17] World Health Organization (2010) Global Recommendations on Physical Activity for Health. World Health Organization, Geneva, 60 p.

[18] WHO Directorate (2000) Global Strategy for the Control of Noncommunicable Diseases. World Health Organization, Geneva, Report No. WHA53/14, 6 p. http://www.who.int/iris/handle/10665/83450

[19] College of Teachers of Cardiology and Vascular Diseases (2011-2012) Item 130: High Blood Pressure in Adults. Francophone Virtual Medical University, 29 p.

http://campus.cerimes.fr/cardiologie-et-maladies-vasulaires/enseignement/cardio 1 30/site/html/cours.pdf

[20] Plouin, P. and Bobrie, G. Severe Hypertension and Hypertensive Emergencies. Hypertension Unit-HEGP, Paris.

[21] Sciences et Avenir (2014) Arterial Hypertension: Definition, Symptoms, Treatment. https://www.sciencesetavenir.fr/sante/systeme-sanguin/hypertension-arterielle-defi nition-symptomes-traitement 12920

[22] Zisimopoulou, S., Pechère-Bertschi, A. and Guessous, I. (2017) Arterial Hypertension. HUG, Geneve, 16.

[23] Ministry of Health and Social Action (2015) Senegal STEPS 2015 Survey: Summary note. Ministry of Health and Social Action, Dakar.

[24] College of Teachers of Vascular Medicine and Vascular Surgery (2010-2011) Item 133: Cerebral Vascular Accidents (CVA). French-Speaking Virtual Medical University, $16 \mathrm{p}$.

http://campus.cerimes.fr/medecine-vasculaire/enseignement/vasculaire 133/site/ht $\mathrm{ml} /$ cours.pdf

[25] Burkina Faso Ministry of Health (2014) Report of the National STEP Survey on the Prevalence of the Main Risk Factors Common to Non-Communicable Diseases in Burkina Faso, 2013. Ministry of Health, Ouagadougou, 104.

[26] Ministry of Health of Côte d'Ivoire (2005) Summary Note of the STEPS Survey Report: Assessment of Risk Factors for Non-Communicable Diseases in Côte d'Ivoire. 
Ministry of Health, Abidjan, 1.

[27] Ministry of Health of TOGO (2012) Non-Communicable Diseases Service of the Epidemiology Division, Agoudavi K. Final report of the STEPS Togo 2010 survey. Ministry of health, Lomé, 188.

[28] Mali Ministry of Health, National Directorate of Health (2008) STEPS Survey Report: Assessment of Risk Factors for Noncommunicable Diseases at Three Sites in Mali. Ministry of Health, Mali, 16.

[29] Ministry of Health of the Islamic Republic of Mauritania (2006) WHO STEPwise Noncommunicable Disease Survey: A Study of High Blood Pressure, Diabetes and Other Risk Factors. Ministry of Health, Nouakchott, 156.

[30] Benin Ministry of Health, National Directorate of Health Protection, National Program for the Control of Noncommunicable Diseases (2007) Final Report of the STEPS Survey in Benin, Cotonou 2007. Benin Ministry of Health, Cotonou, 101.

[31] Masson, E. (2012) Prevalence of Hypertension and Associated Risk Factors in Benin. EM-Consult. Revue d’ Épidémiologie et de Santé Publique, 60, 95-102.

https://doi.org/10.1016/j.respe.2011.09.010

https://www.em-consulte.com/article/702894/prevalence-of-hypertension-and-asso ciated-risk-fac

[32] Masson, E. (2009) Prevalence of Conventional Cardiovascular Risk Factors in the Population of Greater Tunis. Revue d' Épidémiologie et de Santé Publique, 57, 87-92. https://doi.org/10.1016/j.respe.2008.12.010 https://www.em-consulte.com/article/211844/prevalence-des-facteurs-de-risque-car diovasulaire

[33] Masson, E. (2014) Predictors of Mortality in Patients Admitted to Medical Emergencies at University Clinics in Kinshasa. Revue dépidémiologie et de Santé Publique, 62, 15-25. https://doi.org/10.1016/j.respe.2013.11.071

https://www.em-consulte.com/article/868055/facteurs-predictifs-de-la-mortalite-de s-patients-a

[34] Masson, E. (2012) Evolution of Admissions for Cardiovascular Diseases in a Cardiological Environment in Lomé: Cross-Sectional Study of 7959 Patients from June 2004 to May 2009. Revue d’ Épidémiologie et de Santé Publique, 60, 205-211. https://doi.org/10.1016/j.respe.2012.02.002 https://www.em-consulte.com/article/728049/evolution-des-admissions-pour-mala dies-cardiovascu 